\title{
On board Driver Monitoring System with Safety Enhanced Brake System
}

\author{
Dineshkumar C, Subramanian M, Dinesh B, Sonya A, Hemavathy P.R, Arvinda Pandian C.K
}

\begin{abstract}
Recent automobile vehicles require additional safety features to enhance the active safety. Due to lack of safety systems in vehicles road accidents are on the rise. The major cause of collision far $80 \%$ of accidents is drivers fault as cited by the ministry of road accidents of India. The current research work is carried out to analyze the fault of the driver and to measures the health condition of the driver by placing throb sensor and temperature sensor in steering wheel so as to slow down the vehicle by using Jake brake during abnormal health issue. The proposed systems were analyzed for different category of the condition of driver to improve the safety system technology. When triggered the exhaust valve is opened after the compression stroke enable to escape of compressed air from the cylinders to slowdown the vehicle which prevents the accidents in emergency situations.
\end{abstract}

Keywords - Throb sensor, Temperature sensor, Jake brake.

\section{INTRODUCTION}

The brake system is designed to slow down and halt the motion of the vehicle. The automotive braking system had been developed in present days due to large number of accidents happened during health issues. The coordination of sensor technology developed to reduce the speed of the vehicle during emergency. The luxury vehicles had imposed by sensors to park the vehicle, stop the vehicle automatically, steer the vehicle automatically etc. In present day most of the vehicles depends on safety and features to enhance the customer satisfaction. The vehicle to vehicle communication technology had been developed in many countries and in the event of Indian vehicles no proper communication technology is improved. The vehicle communication is important parameter to enhance the safety to driver and pedestrian. The collision occurs due to high speed and health issues are the main criteria for vehicle industry to improve the vehicle safety. The automotive barking system used in many luxury vehicles not in Indian vehicles due to high cost of the vehicle [1]. The research is concentrate mostly on the drivers who undergo heart attack while driving. Because a recent census shows the more number of accidents occur due to heart failure. The drivers lose the control of the vehicle during the heart attack and it may lead to accidents. The proposed research planned to monitor the heart beat rate of the driver of the age group above 40 years onboard using a pulse sensor. The pulse sensor senses the heart beat rate and sends the data to the arduino board which interprets the data already fed in the board and gives out a signal when the heart beat rate falls or increases with the set limit. By monitoring the heart beat, the on board passengers can be prevented from the greater impact of accidents.
The arduino board sends out the warning signal to the dash board and also gives out a buzzing sound from the buzzer. As the health related issues are increasing day today and the need of enhance active safety system for an accurate and affordable heart rate measuring device or heart monitor is essential to ensure quality of health. Commonly most health related measuring tools and atmosphere are expensive and they do not follow the safety and ergonomics. The accidents are the unpleasant event that no one ever wants to occur in their life and it ruins the life of much people causing tremendous losing the life of people. Preventing the accident (accident prevention) refers to activities designed to foresee and avoid accidents. There has been an increase of $17.4 \%$ in the total number of death rate caused by road accidents during the period of 2011-2014. This percentage has raised eyebrows and caught the attention of many to curb the growing rate. It is found that $80 \%$ of the times it is the fault of the driver [2]. Much prevention system has been so far suggested and some were successful to a few percentages. But unfortunately still the accident rate remains a mysterious and very serious problem yet to be solved. So we suggest a technique to prevent accident by alcohol sensor since most of the accident occurring today is mainly because of drunk and drive. In order to avoid rash driving we go for a new technique of speed reduction system which uses the ultrasonic waves fitted to the vehicle to detect the obstacles and the distance they are apart from which we could reduce the speed of the vehicle automatically if the obstacles are present mere closer. In recent times automobile accidents are increasing day by day. This mainly happens when the driver is, drowsy or if he is alcoholic or if he is physically ill [4]. Prevention of accidents remains on one side as a huge question mark but rather on the other we look up for something as a life saving measures to safeguard our self in case of occurrence of any accidents. Many lives would have been saved if the emergency service could get the crash information in time. According to WHO (World Health Organization) reports, age of 35+ people will face Myocardial infarction [Heart attack] at anytime. Unfortunately we've that $8 \%$ of road accidents because of the drive health issues "Reported by NSC [National Safety council].so we plan to monitor the drive health (mode) biologically with help of drive's pulse rate. The below table 1 and figure 1 . Shows the factors responsible for road accidents on Indian roads during the year 2016. The percentage of drivers fault is $41 \%$ and $12 \%$ of health issues fatal accidents in India and the different cause of road accidents leads to fatality is shown below [5]. science and technology, Chennai-India.

Subramanian M, Automobile Engineering BSA Crescent institute of science and technology, Chennai-India 
TABLE 1.Factors responsible for Road Accidents on Indian roads in 2016

\begin{tabular}{|c|c|c|c|}
\hline S.No & causes & $\begin{array}{c}\text { \% of } \\
\text { Fatality }\end{array}$ & $\begin{array}{c}\text { Persons } \\
\text { killed }\end{array}$ \\
\hline $\mathbf{1}$ & Fault of Driver & 41 & $1,21,126$ \\
\hline $\mathbf{2}$ & Fault of Pedestrian & 1.01 & 3091 \\
\hline $\mathbf{3}$ & Mechanical Defect & 0.96 & 2823 \\
\hline $\mathbf{4}$ & Health issues & 12 & 30246 \\
\hline $\mathbf{5}$ & Stray Animal & 0.25 & 629 \\
\hline $\mathbf{6}$ & Exceeding lawful speed & 30 & 73896 \\
\hline $\mathbf{7}$ & Intake of Alcohol & 2.58 & 6131 \\
\hline $\mathbf{8}$ & Overtaking & 3.95 & 9462 \\
\hline $\mathbf{9}$ & Mobile phones & 0.91 & 2138 \\
\hline $\mathbf{1 0}$ & Asleep or fatigued & 0.75 & 1796 \\
\hline $\mathbf{1 1}$ & Other improper actions & 7.2 & 17943 \\
\hline
\end{tabular}

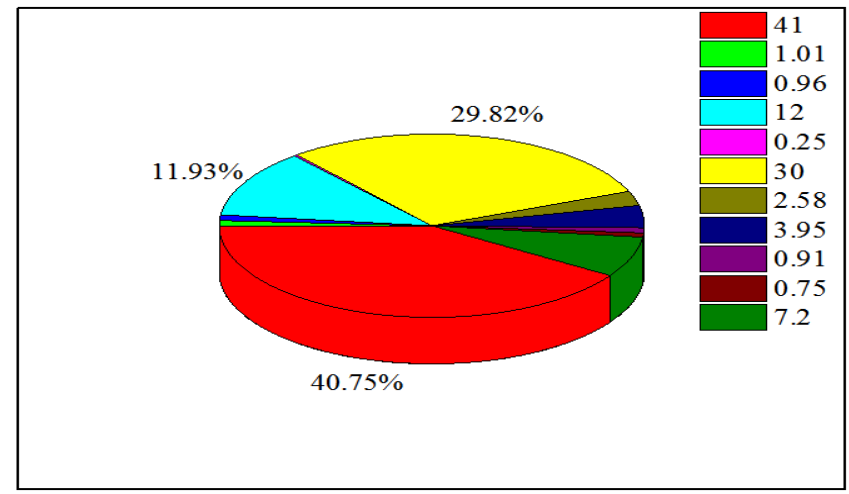

Fig 1. Shows the causes of road accidents in 2016

\section{PROPOSED SYSTEM}

\section{A. positioning of hands}

The positioning of throb sensor in steering wheel by representing survey using 200 peoples for positioning of hand in the steering wheel. The steering wheel is considered as wall clock position. The positing of hand on steering wheel is "4 and 8" and "3 and 9" are the two major used positions. These different hand positions refer to visualizing the steering wheel as the clock face and positioning the left hand at the 9 or 8 and the right hand at the 3 or 4 o'clock position. Today the National Highway Traffic Safety Administration recommends drivers put their hands at the 3 and 9 o'clock positions.

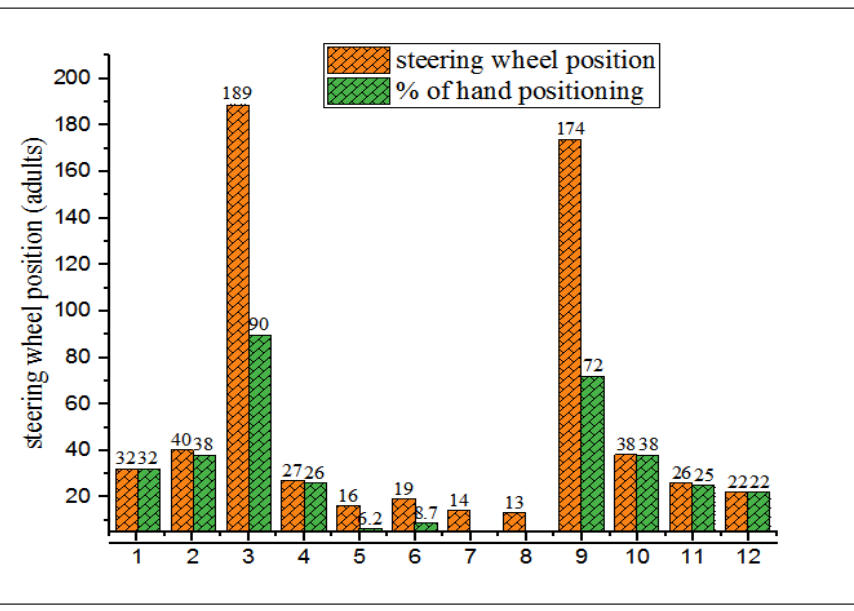

Fig 2. Percentage of Adult position of hands in steering wheel.

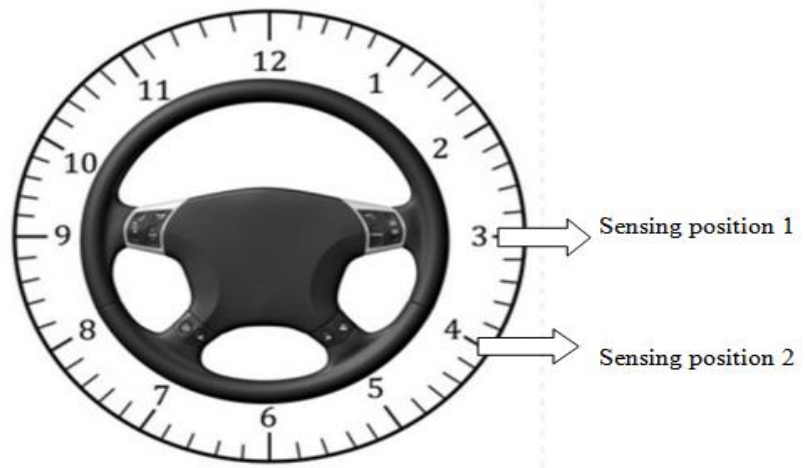

Fig 3.shows the steering wheel sensor position

From the above survey the major holding position of steering wheel is $3 \& 9(82 \%)$ and balance positions are 1 or $2 \%$ depends on situations, still this 1 or $2 \%$ are makeable because we have to monitor every single second. "The age group of above 35+ year's people can be affected by heart issues. The reports by National Safety council [NSC] say $8 \%$ of road accidents happened because of drive health issues. The $8 \%$ of drivers is affected and this $8 \%$ had tones of human, so we have to solve these problems and we planned to place the heart monitoring sensor in steering wheel. Steering wheel is the part which having maximum attention of driving and direct skin contact of drive. So this is the perfect place for heart rate sensor and we did survey with $100+$ drivers on different situations.

\section{B. Control System}

The function of control system of a vehicle can be operated by using an electronic control unit by using heartbeat pulse sensor and temperature sensor which links to steering wheel. The block diagram of a control system of a vehicle is shown in fig 4.The system composed of throb sensor which is used for sensing the pulse rate of the driver during driving the vehicle. The signal from the control unit which is coupled to the controller unit which is used to sense the abnormal pulse rate of the driver. The abnormal pulse rate is measured and this sensor which offers the signal to the electronic control unit. The LM324 IC chip is used for detecting the pulse rate by using IR sensor and it is used for sensing the volume of blood and light is absorbed by the blood and the signal pulse are equivalent to the throb pulse. The heartbeat rate is measured

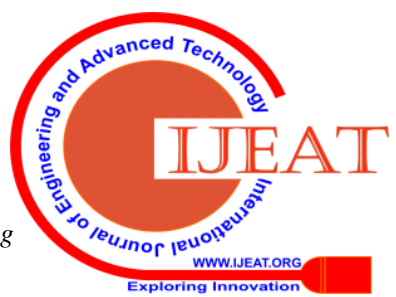


by the pair of LED, LDR and a microcontroller. When the heart pumps the blood pressure varies certainly the infrared light gets reflected back to the detector and the change in voltage pulse. The components are used for the sensing device is resistors, intercom wire, transistor, IR LED emitter and detector, Arduino Uno, ceramic capacitor, tantalum capacitor. Quad op-amp. The completed system is a three wire connection system from sensing part is connected to ardunio board. The system consists of two modes and this mode used to set the range of maximum and minimum pulse rate by manually. The driver who suffered already by health issue or heart attack and he knows the maximum and minimum pulse range as prescribed by doctors already. The control system consists of two modes which are used to measure the abnormal pulse rate and low pulse rate. The pulse range will be displayed in the dashboard during normal health condition of the driver. The pulse rate will be displayed continuously and even co passengers can know the pulse rate of the driver. During abnormal rate the system warns the driver and if he won't response the system gives the signal to the braking system. The output signal from the control unit offers to the solenoid control system to activate the Jake brake. The speed sensor is used to sense the speed of the vehicle and is used to offer the speed of the vehicle during critical situations. The Jake brake is activated depends upon the output signal from the sensor and control unit. The analysed pulse signal from the controller output is linked with the solenoid switch to activate the brake which is used to offer the brake force to apply during emergency situations. The controller consists of display which is used to display the driver's health pulse in the event of danger or emergency situations. The controller system is activates the Jake brake and the Jake brake is controlled by the controller which is placed on the engine head to compress the exhaust valves to open and the compressed air in the cylinder is removed from the cylinders. The air trapped in the cylinder is escaped and this device is operated by the electronic controller module when demand.

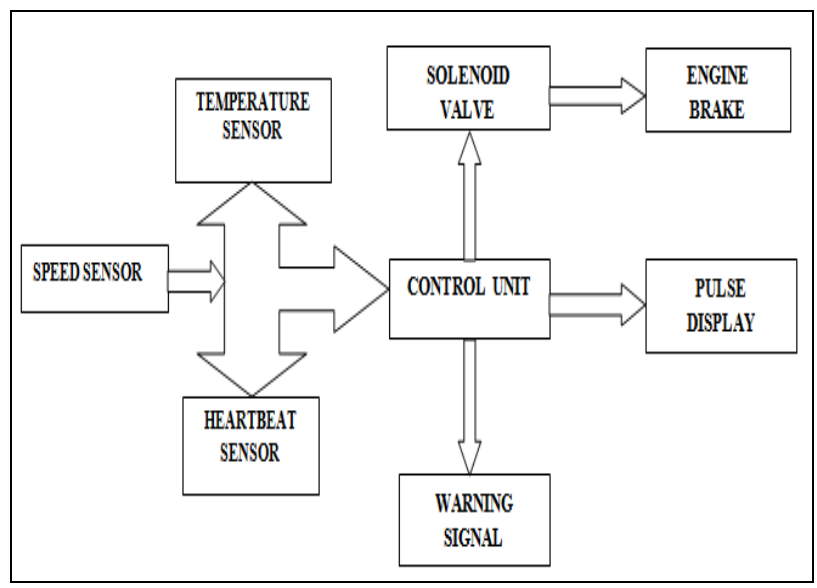

Fig 4. Layout of the controller unit

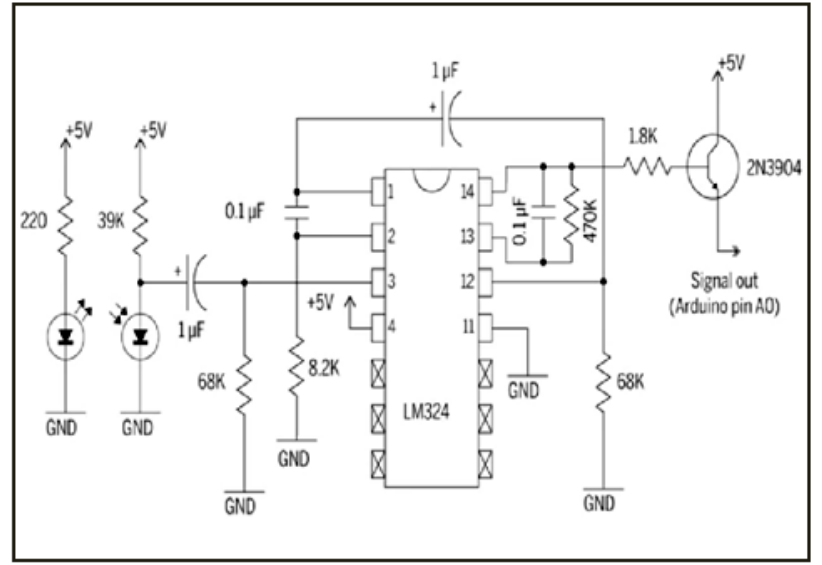

Fig 5. Simplified circuit of a pulse sensing system.

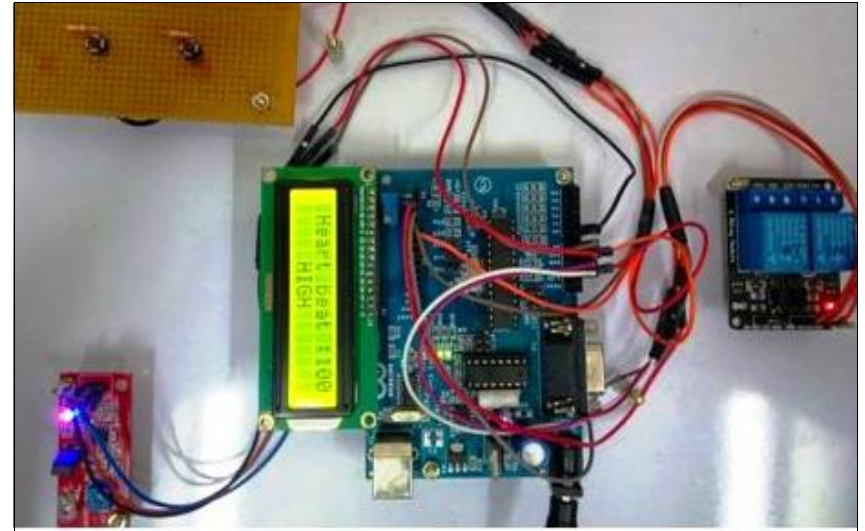

Fig 6. Prototype model of sensing system

TABLE 2. Average pulse rate of the human.

\begin{tabular}{|c|c|c|}
\hline S.No & Age Group & Avg.Pulse rate \\
\hline 1 & New born baby & 140 \\
\hline 2 & 10 years & $85-90$ \\
\hline 3 & 18 years & $80-90$ \\
\hline 4 & Athletes & $40-60$ \\
\hline 5 & $\geq 40$ (adults) & $70-100$ \\
\hline
\end{tabular}

The above table 1 . Reveals the average heart beat of the different groups of human. The adult pulse rate of age group people have focused for this research most commonly heartache problems have occurred generally in adults. In individuals the heart rate and pulse rate have varied due to panic, exercise, excitement, irregular respiration, and mental stress. The common safe heart rate for the individuals can be monitored by using the mathematical relationship. The performance of throb heartbeat sensor is calculated with the output of common usage of ECG [18].

The dignified error rate is -

Here,

$$
\text { Error }[E]=[D-C] \times 100] / D
$$

\section{D- Defined heart rate \\ C- Calculated heart rate \\ E- Error rate}

During compression stroke the compressed air fuel mixture is released Jake brake and it is normally called as Jacobs brake or Jake brake in an engine a braking mechanism is installed on engines. When the Jake brake is released during 
compression stroke and it opens the exhaust valves in the cylinders, it enables the compressed air trapped in the cylinders and makes the vehicle to slowdown during emergency situation. If the vehicle running on a low speed gear the engine rpm is high and then initiate Jake braking the result won't be that good. The process will cause wear on your clutch and transmission. This process is also known as clutch braking and is bad for your car. Often Jake braking is confused with clutch braking. This Jake brake can extend the life of friction brakes and help health issue drivers during critical conditions, maintain better control of their vehicle. For an example it might be an advantage during driving down a steep or long slope. A Jake brake creates braking force by enabling the compressed air inside the cylinders. In contrast, an exhaust brake blocks the path of the exhaust causing an increased pressure in the exhaust manifold. Engine retarders are also known as Jake brakes helps to save the conventional braking system during emergency stopping. Engine brake takes precautions in wear on brakes and supports the driver to keep alive in the event of collision and stability vehicle is increased in the emergency situations. Vigorous use of engine braking by shifting into a lower gear can support to the control speed while driving down very steep and long slopes saving the brakes from overheating and excessive wear. When legalize the engine brake changes the working principle of the engine exhaust valves. The retarding or slowdown the vehicles live axle wheels and allow you to have improved vehicle control without using a service brakes. It is often gossiped that the Jake brake is bad for your car but it can actually proven beneficial by Fenske. Jake brake is more efficient to engine brake because once the throttle is not longer pressed the fuel consumption is decreased. The research is carried out not only to enhance the braking system and to reduce the percentage of the fatality of the fault and health issue of the driver and to improve the braking performance and to supports the service brake of the vehicle.

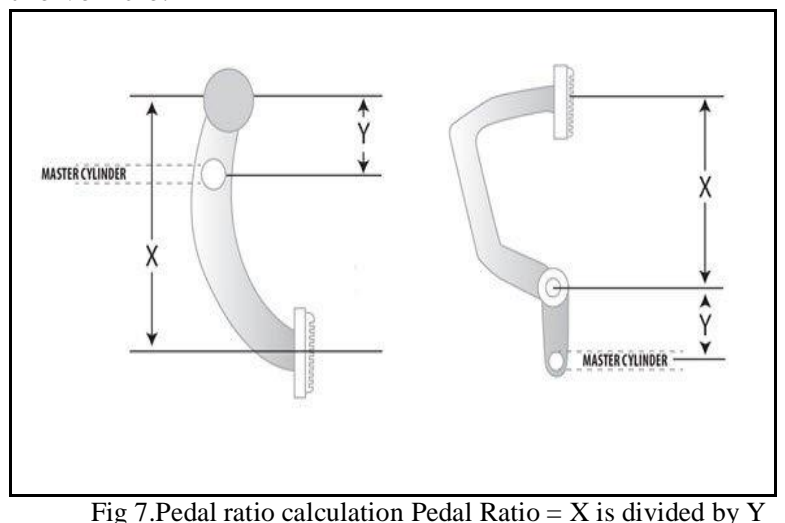

Pedal Ratio is one of the most overlooked parts of a brake system. One of the main reasons and causes of a hard brake pedal is simply due to incorrect pedal ratio. When a brake pedal gets modified to fit in a vehicle or a booster or master cylinder gets installed where it fits in the car, the pedal ratio is rarely taken into consideration. Proper pedal ratio is a must when installing and operating a brake system. The below diagram show how to measure and figure the pedal ratio. In a manual brake system the pedal ratio will be between $5: 1$ and $6: 1$ and a power system will be between $4: 1$ and $5: 1$. In the above illustration of the hanging pedal on the left. Let we assume the overall length of " $\mathrm{X}$ " is 12 " and "Y" measures 3". That puts the pedal ratio at 4:1 which

is perfect for a power system. To make this function as a manual system, the "Y" measurement would need to change to 2 " giving a $6: 1$ ratio.

\section{RESULTS AND DISCUSSIONS}

The sensor offers to measure the health condition of the driver and it depends upon the position of the hand is placed in the steering wheel of the vehicle. The hand position can be varied depends upon the comfort of the driver and sensor senses the pulse rate of the driver during critical condition. The below table shows the different heart rate readings obtained from ECG and proposed system throb sensor for the adult group $\geq 40$. The below table 3 . Shows the different heart beat readings for different age groups which can be obtained from electrocardiogram by measuring the number of different adults under the same age group of 40 . The accuracy level of the throb sensor has maximum error rate of 0.027 shown in the table 3.is compared with electrocardiogram when measured in normal condition. The pulse variation from the control unit make the vehicle tends to slow down by using solenoid control braking which is connected to engine brake. The engine brake is controlled by the control unit of the output signal. The pulse sensor input and health sensor input is monitored and the speed of vehicle is measured and reduced. The solenoid which is coupled with Jake brake in the vehicle and it is activated when the throb sensor offers the signal to the solenoid switch. The braking is activated and triggered depends on the pulse rate and speed sensor.

TABLE 3. Effect of measured heart rate on accurate heart rate

\begin{tabular}{|c|c|c|c|c|c|}
\hline $\begin{array}{c}\text { Age } \\
\text { group }\end{array}$ & $\begin{array}{c}\text { Pulse } \\
\text { rate } \\
(\mathbf{b p m})\end{array}$ & $\begin{array}{c}\text { Actual } \\
\text { rate } \\
(\text { Defined) } \\
\text { ECG } \\
\text { (bpm) }\end{array}$ & $\begin{array}{c}\text { Measured } \\
\text { rate } \\
(\text { Calculate } \\
\mathbf{d}) \\
(\mathbf{b p m})\end{array}$ & $\begin{array}{c}\text { Error } \\
\text { rate } \\
(\%)\end{array}$ & $\begin{array}{c}\text { Abnorm } \\
\text { al Pulse } \\
\text { rate } \\
\text { (bpm) }\end{array}$ \\
\hline 40 & 110 & 74 & 75 & 0.013 & 122 \\
\hline 41 & 110 & 72 & 72 & 0 & 122 \\
\hline 42 & 110 & 73 & 75 & 0.027 & 125 \\
\hline 43 & 110 & 71 & 72 & 0.014 & 128 \\
\hline 44 & 110 & 72 & 73 & 0.013 & 121 \\
\hline 45 & 110 & 73 & 75 & 0.027 & 120 \\
\hline 46 & 110 & 74 & 73 & 0.013 & 123 \\
\hline
\end{tabular}

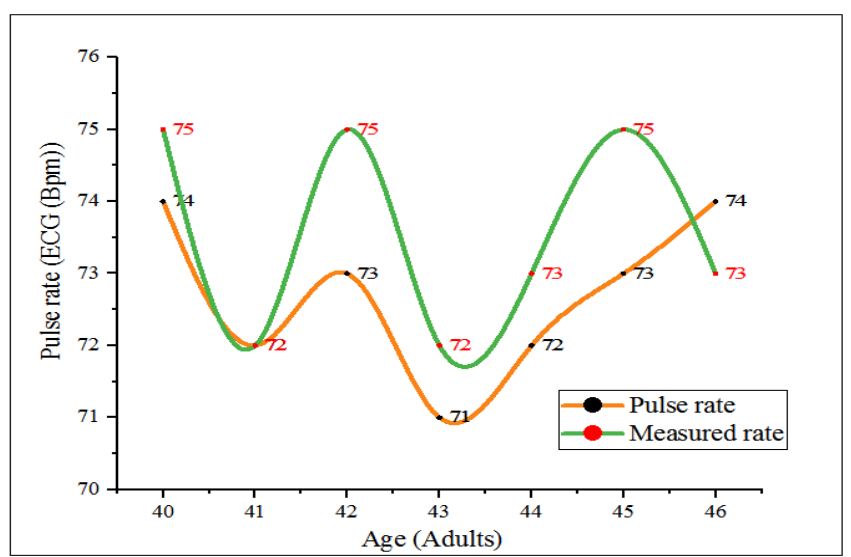

Fig 8.Effect of Adult Age group on pulse rate

Published By: 


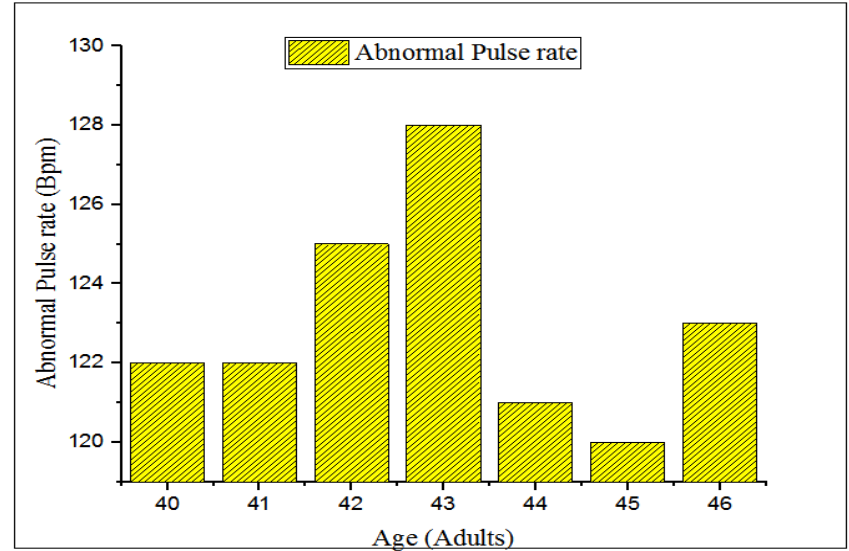

Fig 9.Effect of Adult Age group on abnormal pulse rate

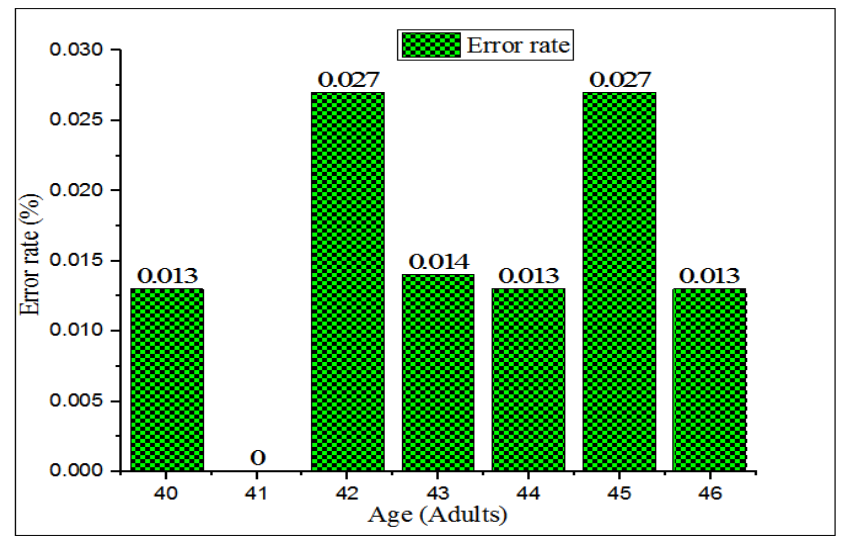

Fig 9.Effect of Adult Age group on Error rate

At the end of the compression cycle the exhaust valve releases brake most commonly confused with real engine braking and used mainly in heavy vehicle. The system works when opening the exhaust valves at the end of the compression cycle the amount of air fuel mixture stored in the engine cylinders and the compressed air is not offers to the engine crankshaft but it is liberating into the ambience. Normally at the end of the compression stroke the energy is used as the piston travelling towards top end compresses the charge inside the cylinder and the compressed charge it acts as a compressed spring and pushes the piston downward. Commonly when the engine brake in operation the compressed charge enables and released the piston towards downward. After removal of the energy stored within the cylinder the compressed charge is not returned the spring back so the engine must expands more energy pulling the piston back down again. The below table 3.shows the comparison of proposed stopping distance and conventional stopping distance with an error rate of the vehicle. The speed of the vehicle is sensed during dynamic condition when the abnormal health is measured the control module offers the signal to the Jake brake to activate. The Jake brake releases the trapped air in the engine cylinder and makes the vehicle to slow down. The braking distance is measured and calculated by the speed of the vehicle. The stopping distance is calculated by considering the reaction distance and thinking distance for the particular vehicle speed. The stopping distance is compared with conventional stopping distance and the error rate is calculated. The error rate shows the vehicle distance covered than the conventional vehicle stopping distance. The maximum error rate is $1.05 \mathrm{~m}$ than the conventional vehicle braking distance and the proposed systems objective is to reduce the vehicle speed than the maximum speed. The reduce speed vehicle impact will be lower than the maximum speed impact during abnormal health condition of the driver while driving the vehicle. The below table shows the comparison of proposed stopping distance and conventional stopping distance with error rate. The vehicle tends to slow down depends upon the speed of the vehicle by using Jake brake. The brake pedal is connected by the hydraulic piston is activated by the controller and which is used to stop down the vehicle. The proposed system activates the engine brake and hydraulic piston linked brake pedal.

TABLE 4.Comparison of proposed automatic vs. conventional manual stopping distance

\begin{tabular}{|c|c|c|c|}
\hline $\begin{array}{c}\text { Vehicle } \\
\text { Speed }\end{array}$ & $\begin{array}{c}\text { Proposed } \\
\text { system } \\
\text { (Automatic) }\end{array}$ & $\begin{array}{c}\text { Conventional } \\
\text { (Manual) }\end{array}$ & $\begin{array}{c}\text { Error } \\
\text { rate }\end{array}$ \\
\hline $\mathbf{k m} / \mathbf{h r}$ & $\begin{array}{c}\text { stopping } \\
\text { distance } \\
\text { (m) }\end{array}$ & $\begin{array}{c}\text { stopping } \\
\text { distance } \\
\text { (m) }\end{array}$ & (m) \\
\hline 10 & 4.10 & 2 & 1.05 \\
\hline 15 & 6.30 & 4 & 0.58 \\
\hline 20 & 8.30 & 6 & 0.38 \\
\hline 25 & 10.30 & 8 & 0.28 \\
\hline 30 & 13.70 & 11 & 0.24 \\
\hline 35 & 16.60 & 14 & 0.19 \\
\hline 40 & 21.70 & 17 & 0.27 \\
\hline
\end{tabular}

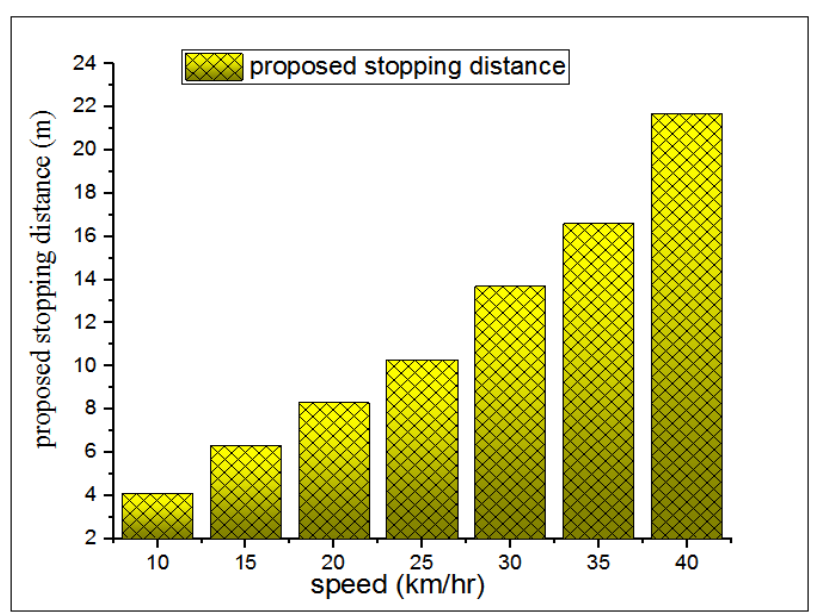

Fig 11. Effect of stopping distance on speed 


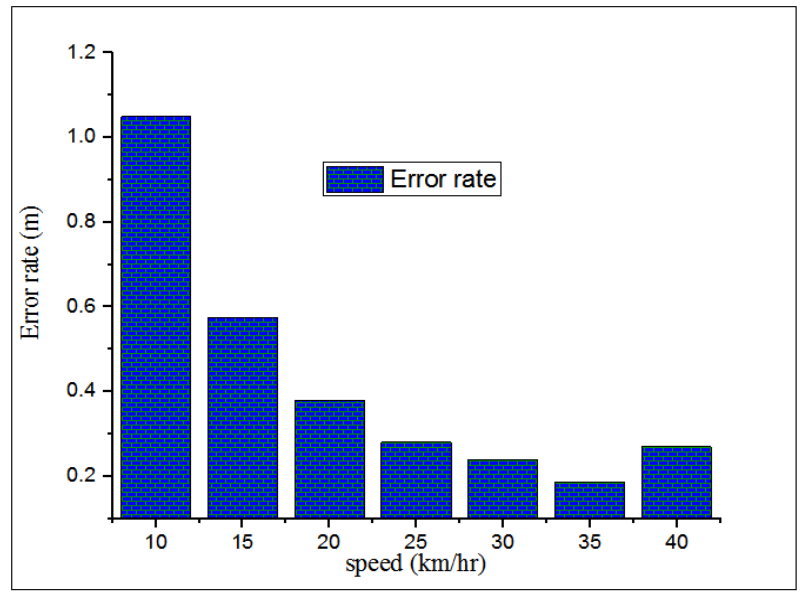

Fig 12. Effect of stopping distance on error rate

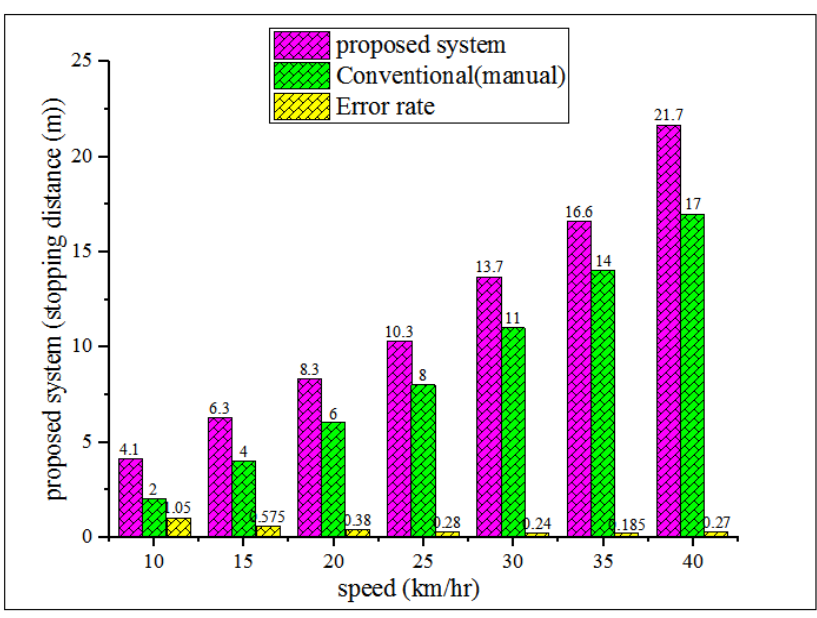

Fig 13.Comparison of proposed (automatic) vs. conventional (manual) stopping distance.

\section{CONCLUSION}

The proposed research monitors the health condition the driver in all critical and normal condition of the driver. The drivers pulse rate is measured by using throb sensor which is displayed in dashboard and everyone can know the pulse range of the driver while driving the vehicle. In the event of any changes in driver health condition the throb sensor shows the fluctuation of the heartbeat range and monitors the pulse rate and displayed in dashboard. The signal from the throb sensor confirms the health issue of the driver and gives the signal to the solenoid switch to activate the engine brake or Jake brake. The Jake brake enables the compressed air in the cylinder and releases the compressed air to the atmosphere. The vehicle speed is controlled or slows down without applying the service brake. The hydraulic piston connected with brake pedal to compress gradually. The vehicle tends to slow down and reduces the impact of the vehicle during the critical situation. The proposed system of this research is measured the abnormal health condition of the driver controlled the vehicle speed during driving in the event of collision. The engine brake enhanced the vehicle control, greater fuel economy and reduced the service brake maintenance.

\section{REFERENCES}

[1] R. Punitha, G. Suchithra, A. Sujitha. Automatic car control during heart attack with an emergency messaging and comprehensive health monitoring system. Volume 6, Issue 1, January-2015.

[2] Ministry of road transport \& highways transport research wing. New Delhi, Road accidents in India - 2015.
[3] Dineshkumar C, Subramanian M “Automotive braking system for passenger vehicle to enhance safety". International Journal of Pure and Applied Mathematics Volume 117 No. 20 2017, 1011-1020 ISSN: 1311-8080 ISSN: 1314-3395 (on-line version). (2018).

[4] B.Praveen Kumar, K. Mahendrakan, "Prevention of Accident due to Drowsy by using Eye blink, International Journal of Innovative Research in Science, Engineering and Technology. Volume 3, Issue 5, May 2014.

[5] Road Accidents in India -Government of India Ministry of Road Transport \& Highways Transport Research Wing New Delhi. 2016.

[6] Sales K. Jose, X. Anitha Mary, Namitha Mathew, "ARM-7 Based Accident Alert and vehicle Tracking System, International Journal of Innovative Technology and Exploring Engineering (IJITEE), Volume 2, Issue 4, March 2013.

[7] Highlights of 2009 Motor Vehicle crashes, Traffic Safety Facts, Research Notes, NHTSA (National Highway traffic Safety Administration). [Online] Accessed on 16 October 2011.

[8] Veena.S.L1, R.Subhashini2 Driver Alertness Based on Eye Blinking and Bio-signals. International Journal of Advanced Research (2014), Volume 2, Issue 3, 666-670

[9] Andreas Meiera, Mark Gontera, Rudolf Kruse "Precrash classification of car accidents for improved occupant safety systems".2014.

[10] Herman A. Hamersma P. Schalk Els- Improving the braking performance of a vehicle with ABS and a semi-active suspension system on a rough road. 28 September 2014.

[11] Rajiv Ranjan Singha, Sailesh Conjetia, Rahul Banerjeeb- "A comparative evaluation of neural network classifiers for stress level analysis of automotive drivers using physiological signals". Biomedical Signal Processing, Elsevier Volume 8, Issue 6, November 2013, Pages 740-754.

[12] V. Deepan, M. Subramanian, C. Dineshkumar "Motorcycle rider fatigue analyse: Results of an Online Survey" International Journal of Mechanical and Production Engineering Research and Development (IJMPERD) ISSN (P): 2249-6890; ISSN (E): 2249-8001 Vol. 8, 2018.

[13] M.M.A. Hashem, Rushdi Shams, Md. Abdul Kader, and Md. Abu Sayed. "Design and Development of a Heart Rate Measuring Device using Fingertip" (KUET) Khulna 9203, 2015 Bangladesh.

[14] Dineshkumar C, Subramanian M "Experimental Investigation of Onboard Driver Condition Monitoring System for Passenger Vehicles" International Journal of Mechanical Engineering and Technology (IJMET) Volume9, Issue6, June 2018, pp.01-09. Article ID: IJMET_06_07_001.

[15] Lori Mooren,Raphael Grzebieta, Ann Williamson, Jake Olivier Rena Friswell "Safety management for heavy vehicle transport: A review of the literature" Volume 62, February 2014, Pages 79-89.

[16] Herman A. Hamersma, P. Schalk Els "Improving the braking performance of a vehicle with ABS and a semi-active suspension system on a rough road" Journal of Terra mechanics Department of Mechanical and Aeronautical Engineering, University of Pretoria, South Africa. Volume 56 (2014) 91-101.

[17] ${ }^{1}$ Dineshkumar C, ${ }^{2}$ Subramanian M, ${ }^{3}$ Jenorish Muthaya, ${ }^{4}$ Deepan V "Health Monitoring System for Automobile Vehicles to Enhance Safety" International journal of vehicle structure and systems, Article in press Volume 10, Issue 6.2018.

[18] C. K. Arvinda Pandian, H. Siddhi Jailani, "Investigation of viscoelastic attributes and vibrational characteristics of natural fabrics-incorporated hybrid laminate beams", Polymer Bulletin. 2018, Vol. 75 (5), pp 1997-2014

[19] C. K. Arvinda Pandian, H. Siddhi Jailani, A. Rajadurai, "Natural fabric sandwich laminate composites: development and investigation", Bulletin of Materials Science. 2017, Vol. 40 (1), pp 139-146. 